\title{
Survival and reoperation after valve-sparing root replacement and root repair in acute type A dissection
}

\author{
Hans-Hinrich Sievers, MD, Doreen Richardt, MD, Michael Diwoky, Christian Auer, MD, \\ Bence Bucsky, MD, Boris Nasseri, MD, and Stefan Klotz, MD
}

\section{ABSTRACT}

Objective: Optimal treatment of the dissected root in type A dissection is still controversial. Valve-sparing techniques offer the advantage of better valve performance compared with mechanical valves or bioprostheses. The role of the different valve-preserving methods - root repair and replacement-needs further evaluation.

Methods: Follow-up data (median follow-up, 11.4 years; 95\% confidence interval [CI], 10.1-12.7; range, 0-22.1 years) of 179 patients with acute type A dissection and root involvement, who underwent a valve-sparing root replacement using reimplantation $(n=44)$ or remodeling $(n=39)$ or a valve-sparing root repair ( $n=96$ ) between 1993 and 2017 were analyzed with respect to survival and reoperation.

Results: Median age of patients with reimplantation was 56.9 (range, 20.2-78), with remodeling 62.6 (range, 31-79.1), and with valve-sparing root repair 64.5 (range, 31$89.6)$ years. Thirty-day mortality for these groups was $15.9 \%, 15.4 \%$, and $12.5 \%$ $(P=.829)$, late mortality at 15 years was $43.2 \%(95 \% \mathrm{CI}, 28.1-66.5), 36.7 \%$ (95\% CI, 19.7-68.1), and 36.5\% (95\% CI, 23.0-57.9; $P=.504)$. Risk factors for overall mortality were age, connective tissue disease, total arch replacement, surgical time, cross-clamp time, circulatory arrest, and the reimplantation technique. Cumulative incidence of reoperation at 15 years was $13.4 \%$ (95\% CI, 2.1-24.7), $20 \%$ (95\% CI, 6.3-33.6), and 13.3\% (95\% CI, 4.8-21.7; $P=.565)$, respectively.

Conclusions: With the different conditions in each group in this study on patients with acute type A dissection the valve-preserving root repair technique has similar long-term rates of survival and reoperation compared with root replacement techniques, underlining its usefulness as a less complex and even faster surgical technique if individually indicated. (J Thorac Cardiovasc Surg 2018;156:2076-82)

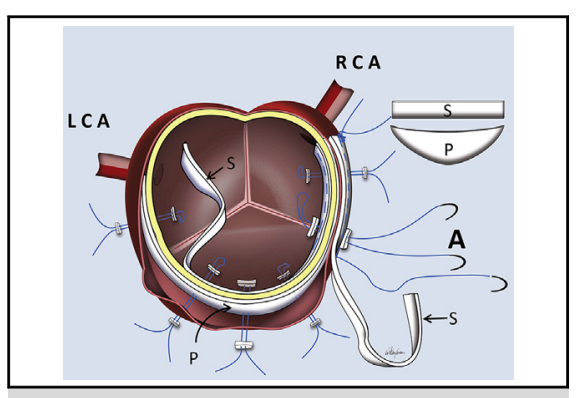

Technique of valve-sparing root repair using a Teflon inlay patch for root stabilization.

Central Message
Considering the different conditions in each
group in this study we found no difference in re-
operation and survival rates between root repair
and valve-sparing root replacement techniques.
Perspective
Acute type A dissection is a devastating disease
with complex pathology. Emergent surgery
aims primarily at achieving survival. Individu-
alized approach, related to extent of pathology,
patient's condition, and surgeon's experience
might include valve-sparing root repair as a
less complex and time-saving technique.
Longer-term multicenter follow-up is desirable
to verify this strategy.

See Editorial Commentary page 2083.
Optimal treatment of the dissected aortic root in acute type A dissection (AAD) is still controversial. ${ }^{1-4}$ The options include root repair with valve replacement or complete root replacement with conduits containing a bioprosthesis or a mechanical valve (Bentall procedure) $)^{5}$ or valve-

\footnotetext{
From the Department of Cardiac and Thoracic Vascular Surgery, University Medical Center Schleswig-Holstein, Campus Lübeck, Luebeck, Germany.

Drs Sievers and Richardt contributed equally to this work.

Received for publication Dec 21, 2017; revisions received May 15, 2018; accepted for publication May 25, 2018; available ahead of print July 6, 2018.

Address for reprints: Hans-Hinrich Sievers, MD, Department of Cardiac and Thoracic Vascular Surgery, University Medical Center Schleswig-Holstein, Campus Luebeck, Ratzeburger Allee 160, Luebeck 23538, Germany (E-mail: Hans-Hinrich. Sievers@uksh.de).

$0022-5223 / \$ 36.00$

Copyright (c) 2018 by The American Association for Thoracic Surgery

https://doi.org/10.1016/j.jtcvs.2018.05.096
}

sparing root replacement using the David reimplantation ${ }^{6}$ or the Yacoub remodeling ${ }^{7}$ technique or conservative valve-sparing root repair. The latter 3 methods have the advantage of retaining autologous leaflets favoring longterm durability with low risk of thromboembolism and avoiding the shortcomings of mechanical valves or bioprostheses $^{8-10}$ with more frequent use in the past decade. $^{11}$ Midterm and long-term results with the David procedure are reported to be excellent. ${ }^{1-3,12,13}$ There are,

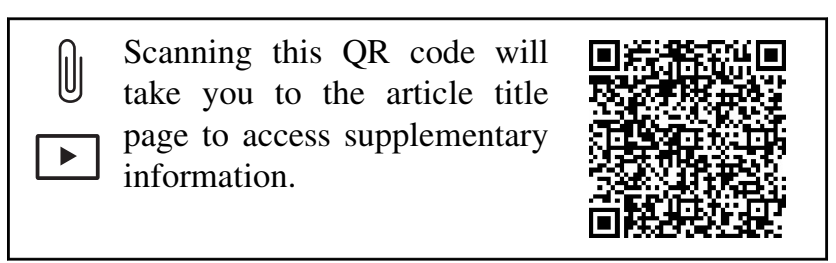




\section{Abbreviations and Acronyms \\ $\mathrm{AAD}=$ acute type $\mathrm{A}$ dissection \\ $\mathrm{CI}=$ confidence interval \\ $\mathrm{GRF}=$ gelatin-resorcinol-formaldehyde \\ $\mathrm{HR}=$ hazard ratio}

however, no long-term results on the different aortic valve preserving root replacement techniques compared with the more conservative valve-sparing root repair. These techniques differ considerably in indication and surgical complexity stimulating the question on their role in the treatment of dissected roots. For this judgement longterm results are desirable. We report our 20 years' experience with the 3 different valve-sparing root procedures in AAD.

\section{METHODS}

From August 1993 to May 2017, 406 patients received surgery for acute or chronic type A dissection at the University of Lübeck. Of these patients 179 with AAD involving also the root underwent valve-sparing procedures either using the reimplantation $(n=44)$ or remodeling technique $(n=39)$ or valve-sparing root repair $(n=96$; Table 1$)$. In the remodeling group not all patients needed a full replacement of all 3 sinuses, 19 patients had complete remodeling with 3 sinuses, 4 patients with 2 sinuses, and 16 patients with 1 sinus, usually the noncoronary sinus. After approval by the ethical committee patients' consent was obtained. Patients were contacted via written questionnaires and telephone calls. Echocardiographic data were acquired from referring cardiologists and outpatient visits. Follow-up was obtained between 2016 and December 2017 and was 100\% complete with a median follow-up of 11.4 years (95\% confidence interval [CI], 10.112.7; range, $0-22.1$ years; 1223.9 cumulative patient-years; reimplantation,
15.8 years [95\% CI, 14.6-16.9], remodeling, 11.8 years [95\% CI, 10.2 13.3], and root repair, 9.3 years [ $95 \% \mathrm{CI}, 7.4-11.2]$ ).

\section{Surgical Technique}

After establishing cardiopulmonary bypass the dissected aorta was transected $1 \mathrm{~cm}$ above the commissures. The valve was inspected and if there were no macroscopically major pathologic alterations of the leaflets (shrinkage, calcification, degeneration, huge fenestrations) a decision was made to preserve the leaflets. The annulus diameter was measured with a Hegar dilator, and if it was more than 28 to $30 \mathrm{~mm}$ in diameter a David reimplantation and if less a Yacoub remodeling procedure was performed in case of dilated sinuses, and in normal-sized roots a valve-sparing root repair (Figure E1). However, preoperative measurement of root dimensions is difficult in the dissected state and direct intraoperative measurement also. So more or less eyeballing and the experience of the surgeon determined the type of procedure and less the previously mentioned diameter-based ideal indications. Twenty-five percent of the remodeling and reimplantation procedures were performed by 1 surgeon (H.-H.S.) and additional 8 more surgeons performed the rest of the procedures. In the first 10 years the dissected area was glued with gelatin-resorcinol-formaldehyde (GRF; Cardial, Saint E'tienne, France) glue before the procedure, and later on GRF glue was used only sporadically because there surfaced some hints that GRF glue might be associated with redissection. ${ }^{14,15}$ In case of remodeling and reimplantation the sinuses were excised leaving a rim of $3 \mathrm{~mm}$ of sinus tissue. Details of the valve-sparing root replacement techniques have been previously reported. ${ }^{16}$ For valve-sparing root repair a sandwich technique was used sometimes combined with GRF or BioGlue (CryoLife, Inc, Kennesaw, Ga). In the past 15 years this technique consisted of an inlay patch (Teflon) between media and adventitia, tailored to the size of the dissection area usually from the left to the right coronary ostia. Two additional strips of the Teflon felt were used as an internal and external layer just above the commissures sutured with continuous mattress 5/0 Prolene, integrating the Teflon patch of the dissection plane. Several single U-stitches with pledgets were stitched from inside the sinus to outside for fixation of the layers. Thereafter the commissures were additionally fixed with $2 / 0$ polyfilament pledgeted sutures (Figure 1). Only in

TABLE 1. Patient demographic characteristics and preoperative status

\begin{tabular}{|c|c|c|c|c|c|}
\hline & $\begin{array}{l}\text { Reimplantation } \\
\quad(n=44)\end{array}$ & $\begin{array}{l}\text { Remodeling } \\
\quad(\mathbf{n}=39)\end{array}$ & $\begin{array}{l}\text { Root repair } \\
(\mathbf{n}=96)\end{array}$ & $P$ value & $\begin{array}{c}\text { Post hoc } \\
\text { comparison }\end{array}$ \\
\hline Age, y & $\begin{array}{l}56.9[43.5-65.8] \\
\text { Range, } 20.2-78\end{array}$ & $\begin{array}{l}62.6[51.8-67.8] \\
\text { Range, } 31-79.1\end{array}$ & $\begin{array}{l}64.5[31-89.6] \\
\text { Range, } 31-89.6\end{array}$ & .002 & * \\
\hline Male sex & $35(79.5)$ & $27(69.2)$ & $56(58.3)$ & .043 & * \\
\hline $\begin{array}{l}\text { Connective tissue disease (Marfan, Loeys-Dietz, } \\
\text { cystic medial necrosis, Erdheim-Gsell) }\end{array}$ & $3(7.1)$ & $2(6.5)$ & $2(2.9)$ & .561 & \\
\hline Previous cardiac surgery & 0 & $3(7.7)$ & $2(2.7)$ & .087 & \\
\hline Diabetes mellitus & $3(6.8)$ & $3(7.7)$ & $5(5.7)$ & .907 & \\
\hline Hypertension & $26(59.1)$ & $21(22.8)$ & $54(51.7)$ & .723 & \\
\hline Dyslipoproteinemia & $9(21.4)$ & $8(21.1)$ & $11(12.9)$ & .364 & \\
\hline Cardiogenic shock & $12(27.3)$ & $9(23.1)$ & $32(33.3)$ & .460 & \\
\hline Resuscitation & $3(6.8)$ & $3(7.7)$ & $6(6.3)$ & .954 & \\
\hline Cerebral symptoms & $1(2.3)$ & $6(15.4)$ & $7(7.3)$ & .082 & \\
\hline Preoperative ventilation & $10(22.7)$ & $2(5.1)$ & $14(14.6)$ & .076 & \\
\hline Inotropic support & $6(13.6)$ & $1(2.6)$ & $21(21.9)$ & .018 & $\dagger$ \\
\hline Type A dissection during PCI & 0 & $6(15.4)$ & $1(1.0)$ & $<.001$ & $\ddagger, \dagger$ \\
\hline
\end{tabular}

Age is shown as median and interquartile ranges and ranges. $P C I$, Percutaneous coronary intervention. ${ }^{*}$ Reimplantation versus root repair, $P<.05$. $\dagger$ Remodeling versus root repair, $P<.05$. ‡Reimplantation versus remodeling, $P<.05$. 
1 case the leaflet coaptation was adjusted using central stitches. Thereafter the Dacron prosthesis for replacing the ascending aorta was sutured to the root. The current management strategy is still on the basis of the experience and preference of the surgeon, the patients' conditions, and the extent of the disease. Especially the David procedure is more complex and timeconsuming compared with the Yacoub remodeling technique, particularly if only 1 or 2 sinuses need replacement, and also compared with the root repair. Furthermore, the fact that more surgeons are involved in these mostly at night performed procedures the fast root repair technique and partial remodeling are preferred in recent years (Figures E1 and E2).

\section{Statistical Analysis}

Categorical data are summarized as absolute and relative frequencies whereas not normally distributed continuous variables are summarized as medians and interquartile ranges and ranges. Normal distribution of continuous data was evaluated by visual inspection of QQ plots and histograms as well as using the Kolmogorov-Smirnov test. Differences between the groups were analyzed using the Kruskal-Wallis test followed by pairwise comparisons with Bonferroni-corrected Dunn post hoc test in nonparametric continuous data. Categorical variables were analyzed using the $\chi^{2}$ test or Fisher exact test as appropriate. The median follow-up time was calculated using the reverse Kaplan-Meier method and completeness of follow-up was using the method described by Clark and colleagues. ${ }^{17}$ Evaluation of survival time was performed using the Kaplan-Meier method and the log rank test. The reoperation rates were calculated using the cumulative incidence function adjusting reoperation for the competing risk of death and were compared using Gray log rank test. Potential risk factors were included in a multivariable Cox proportional hazard analysis using backwards elimination. Additionally surgical technique as a factor of potential relevance was forced in the Cox model. Results of the Cox model were expressed as hazard ratios (HRs) and $95 \%$ CIs. Performance of the model was evaluated by calculating Harrell $\mathrm{C}$ statistics. An $\alpha$ level of 0.05 defined statistical significance. All calculations were performed using IBM version 24 SPSS Statistics for Windows (IBM Corp, Armonk, NY) and R (R Foundation for Statistical Computing, Vienna, Austria; http:// www.R-project.org).

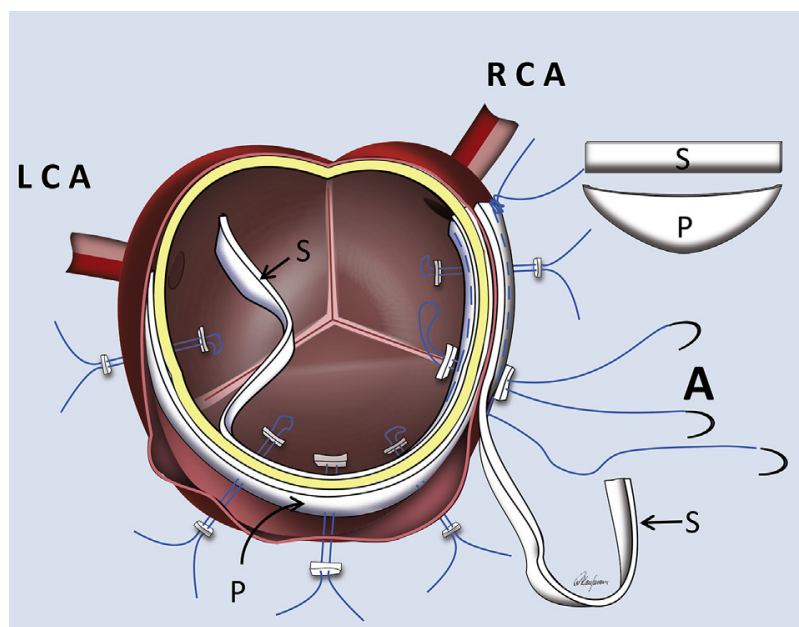

FIGURE 1. Schematic drawing of valve-sparing root repair. The dissected gap between media and adventitia is filled with a previously tailored Teflon patch $(P)$ and buttressed between 2 strips of Teflon $(S)$ internally and externally with $5 / 0$ mattress suture. Additional $2 / 0$ polyfilament sutures fix the commissures $(A)$ and multiple pledget sutures are used to adapt the layers in the area of the sinuses. $L C A$, Left coronary artery; $R C A$, right coronary artery.

\section{RESULTS}

Patient demographic characteristics and preoperative status are shown in Table 1. Comparison of preoperative data showed an imbalance between groups regarding age, male sex, preoperative inotropic support, and the frequency of type A dissection during PCI. Intraoperative data are shown in Table 2.

\section{Early Mortality}

Thirty-day mortality was $14.0 \%$. Seven patients $(15.9 \%)$ of the reimplantation and 6 patients $(15.4 \%)$ of the remodeling group and 12 patient (12.5\%) of the valve-sparing root repair group died within the first 30 days after the surgery $(P=.829)$. The causes of death were cardiogenic shock $(\mathrm{n}=9)$, multiorgan failure $(\mathrm{n}=5)$, cerebral event $(\mathrm{n}=5)$, bleeding $(\mathrm{n}=3)$, myocardial infarction $(\mathrm{n}=2)$, and sepsis $(\mathrm{n}=1)$.

\section{Late Mortality}

Considering patients after the first 30 postoperative days the probability of survival differed not significantly between the 3 treatment groups $(P=.504)$. The survival rates at 5 , 10 , and 15 years were $89.0 \%(95 \% \mathrm{CI}, 79.4-99.8)$, $66.9 \%$ (95\% CI, 52.5-85.3), and $43.2 \%$ (95\% CI, $28.1-$ $66.5)$ for the reimplantation group, $73.1 \%(95 \% \mathrm{CI}, 58.8-$ 91.0), $58.7 \%$ (95\% CI, 43.1-79.8), and $36.7 \%$ (95\% CI, 19.7-68.1) for the remodeling group, and $79.3 \%(95 \%$ CI, 70.4-89.3), 53.2\% (95\% CI, 41.2-68.6), and 36.5\% (95\% CI, 23.0-57.9) for the valve-sparing root repair group. The reasons for late death in the reimplantation, remodeling, and valve-sparing root repair groups were cardiac in $6(35.3 \%), 11(68.8 \%)$, and $6(18.2 \%)$ patients, noncardiac in $10(58.8 \%), 5(31.3 \%)$, and $18(54.5 \%)$ patients, and unknown in $1(5.9 \%), 0$, and $9(27.3 \%)$ patients, respectively $(P=.003)$.

\section{Overall Mortality}

Overall survival curves including the first 30-day mortality for all patients of the 3 treatment groups are depicted in Figure 2 . The difference in survival time was not significant between the groups $(P=.706)$. At 5,10 , and 15 years the survival rates were $74.9 \%$ (95\% CI, 63.0-88.9), 56.3\% (95\% CI, 42.8-74.0), and 36.3\% (95\% CI, 23.2-57.0) for the reimplantation group, $61.9 \%(95 \%$ CI, 47.9-80.0), $49.6 \%$ (95\% CI, 35.5-69.4), and 31.0\% (95\% CI, 16.5 $58.4)$ for the remodeling group and $69.4 \%(95 \% \mathrm{CI}$, $60.2-79.9), 46.5 \%$ (95\% CI, 35.7-60.7), and 31.9\% (95\% CI, 20.0-50.9) for the valve-sparing root repair group.

The multivariable Cox analysis revealed age (HR, 1.048; 95\% CI, 1.024-1.073; $P<.001)$, connective tissue disease (HR, 3.847; 95\% CI, 1.303-11.363; $P=.015$ ), total arch replacement (HR, 8.817; 95\% CI, 3.014-25.789; $P<.001$ ), surgical time (HR, 1.003; 95\% CI, 1.001-1.005; 
TABLE 2. Intraoperative data

\begin{tabular}{|c|c|c|c|c|c|}
\hline & $\begin{array}{l}\text { Reimplantation } \\
\quad(n=44)\end{array}$ & $\begin{array}{l}\text { Remodeling } \\
(\mathbf{n}=39)\end{array}$ & $\begin{array}{l}\text { Root repair } \\
(\mathbf{n}=96)\end{array}$ & $P$ value & $\begin{array}{l}\text { Post hoc } \\
\text { comparison }\end{array}$ \\
\hline Aortic arch procedures & & & & .141 & \\
\hline Hemiarch replacement & $17(38.6)$ & $20(51.3)$ & $41(42.7)$ & & \\
\hline Total arch replacement & $6(13.6)$ & $2(5.1)$ & $7(7.3)$ & & \\
\hline Aortic arch repair & $10(22.7)$ & $6(15.4)$ & $33(34.4)$ & & \\
\hline Bicuspid aortic valve & $1(2.3)$ & 0 & $2(2.1)$ & .652 & \\
\hline CABG & $7(15.9)$ & $10(25.6)$ & $8(8.3)$ & .029 & \\
\hline Surgery time, minutes & $\begin{array}{c}395[336-486] \\
\text { Range, } 276-717\end{array}$ & $\begin{array}{c}389[314-441] \\
\text { Range, } 235-1298\end{array}$ & $\begin{array}{c}356[281-420] \\
\text { Range, } 183-1055\end{array}$ & .011 & * \\
\hline Cardiopulmonary bypass time, minutes & $\begin{array}{l}249[211-289] \\
\text { Range } 164-378\end{array}$ & $\begin{array}{c}213[174-253] \\
\text { Range, } 120-876\end{array}$ & $\begin{array}{l}195[151-249] \\
\text { Range, 91-573 }\end{array}$ & $<.001$ & $*, \dagger$ \\
\hline Cross-clamp time, minutes & $\begin{array}{c}188[158-222] \\
\text { Range, } 110-303\end{array}$ & $\begin{array}{l}154[125-185] \\
\text { Range, } 70-612\end{array}$ & $\begin{array}{c}119[91-157] \\
\text { Range, } 34-456\end{array}$ & $<.001$ & $*, \dagger, \ddagger$ \\
\hline $\begin{array}{l}\text { Circulatory arrest, } \mathrm{n} \\
\text { Circulatory arrest time, minutes }\end{array}$ & $\begin{array}{c}42(95.5) \\
34[26-58] \\
\text { Range, } 15-191\end{array}$ & $\begin{array}{c}34(87.2) \\
37[26-46] \\
\text { Range, 12-100 }\end{array}$ & $\begin{array}{c}85(88.5) \\
40[27-59] \\
\text { Range, } 4-300\end{array}$ & .508 & \\
\hline $\begin{array}{l}\text { Arterial cannulation site } \\
\text { Central } \\
\text { Peripheral } \\
\text { Combination }\end{array}$ & $\begin{array}{c}17(38.6) \\
27(61.4) \\
0\end{array}$ & $\begin{aligned} 9 & (23.1) \\
29 & (74.4) \\
1 & (2.6)\end{aligned}$ & $\begin{array}{c}19(19.8) \\
77(80.2) \\
0\end{array}$ & .052 & \\
\hline $\begin{array}{l}\text { Venous cannulation site } \\
\text { Central } \\
\text { Peripheral }\end{array}$ & $\begin{array}{c}42(95.5) \\
2(4.5)\end{array}$ & $\begin{array}{c}37(94.9) \\
2(5.1)\end{array}$ & $\begin{array}{c}90(93.8) \\
6(6.3)\end{array}$ & .911 & \\
\hline
\end{tabular}

Central arterial cannulation means cannulation of the aortic arch in the nondissected area, peripheral means cannulation of the subclavian or the femoral artery. Time-related variables are shown as medians and interquartile ranges and ranges. $C A B G$, Coronary artery bypass grafting. * Reimplantation versus root repair, $P<.05$. $\dagger$ Reimplantation versus remodeling, $P<.05$. ‡Remodeling versus root repair, $P<.05$.

$P=.002)$, cross-clamp time (HR, 0.991; 95\% CI, 0.985$0.998 ; P=.011)$, circulatory arrest (HR, $0.313 ; 95 \% \mathrm{CI}$, $0.130-0.753 ; P=.009$ ), and the reimplantation technique (HR, 2.247; 95\% CI, 1.019-4.954; $P=.045$ ) as risk factors for overall mortality (Table 3 ). Harrell C statistic value was 0.72 .

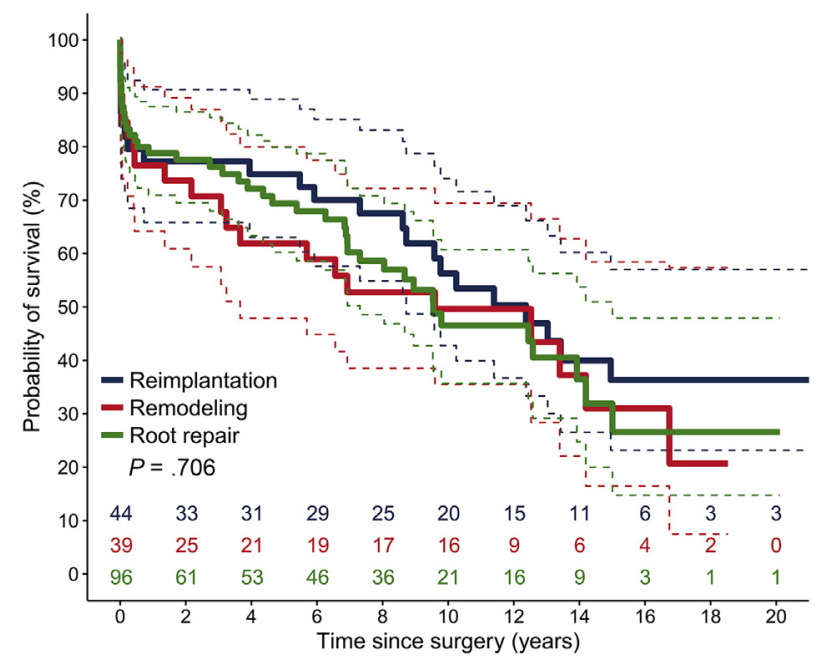

FIGURE 2. Probability of survival stratified according to the different surgical techniques.

\section{Reoperation}

The 5-, 10-, and 15-year cumulative incidence rates of aortic root reoperation were $4.8 \%(95 \% \mathrm{CI}, 0-11.3)$, $10.1 \% \quad(95 \%$ CI, $0.5-19.8)$, and $13.4 \% \quad(95 \% \quad \mathrm{CI}$, 2.1-24.7) for the reimplantation group, $16.6 \%(95 \% \mathrm{CI}$, $4.2-29), 16.6 \%$ (95\% CI, 4.2-29), and $20 \%(95 \% \mathrm{CI}$, 6.3-33.6) for the remodeling group, and $7.8 \%(95 \% \mathrm{CI}$, $1.8-13.8), 10.9 \%(95 \% \mathrm{CI}, 3.7-18.1)$, and $13.3 \%(95 \%$ CI, 4.8-21.7) for the valve-sparing root repair group and was not significantly different between the groups $(P=.565$; Figure 3$)$. The reasons for reoperation are shown in Table E1. There were 2 hospital deaths in the 22 reoperated patients $(\mathrm{n}=1$ primary reimplantation procedure, $\mathrm{n}=1$ primary root repair). Univariate Cox regression model for reoperation revealed a HR of $3.942(95 \%$ CI, 0.984-15.798; $P=.053$ ) for GRF use in the root repair group.

\section{Aortic Valve Function}

Early postoperative echocardiographic investigation of aortic regurgitation was available in $136(76.0 \%)$ patients. One hundred twenty-six patients $(92.6 \%)$ had none or trace aortic regurgitation after surgery, $8(5.9 \%)$ had a mild degree, and in $2(1.5 \%)$ patients there was a moderate degree of aortic regurgitation. Current echocardiographic 
TABLE 3. Cox multivariable analysis of risk factors for survival

\begin{tabular}{|c|c|c|}
\hline Variable & $\begin{array}{l}\text { Hazard ratio } \\
(95 \% \mathrm{CI})\end{array}$ & $P$ value \\
\hline \multicolumn{3}{|l|}{ Surgical technique } \\
\hline Valve-sparing root repair & Reference & \\
\hline Reimplantation & $2.247(1.019-4.954)$ & .045 \\
\hline Remodeling & $1.625(0.793-3.333)$ & .185 \\
\hline Age & $1.048(1.024-1.073)$ & $<.001$ \\
\hline Male sex & & n.s. \\
\hline Connective tissue disease & $3.847(1.303-11.363)$ & .015 \\
\hline Diabetes & & n.s. \\
\hline Hypertension & & n.s. \\
\hline Dyslipoproteinemia & & n.s. \\
\hline Cardiogenic shock & & n.s. \\
\hline Resuscitation & & n.s. \\
\hline Cerebral symptoms & & n.s. \\
\hline Preoperative ventilation & & n.s. \\
\hline Inotropic support & & n.s. \\
\hline Type A dissection during PCI & & n.s. \\
\hline \multicolumn{3}{|l|}{ Aortic arch procedures } \\
\hline Hemiarch replacement & $1.261(0.549-2.894)$ & .585 \\
\hline Total arch replacement & $8.817(3.014-25.789)$ & $<.001$ \\
\hline Aortic arch repair & $0.850(0.369-1.960)$ & .703 \\
\hline CABG & & n.s. \\
\hline Surgery time, minutes & $1.003(1.001-1.005)$ & .002 \\
\hline $\begin{array}{l}\text { Cardiopulmonary bypass } \\
\text { time, minutes }\end{array}$ & & n.s. \\
\hline Cross-clamp time, minutes & $0.991(0.985-0.998)$ & .011 \\
\hline $\begin{array}{l}\text { Circulatory arrest, } \mathrm{n} \\
\text { Circulatory arrest time, } \\
\text { minutes }\end{array}$ & $0.313(0.130-0.753)$ & $\begin{array}{l}.009 \\
\text { n.s. }\end{array}$ \\
\hline $\begin{array}{l}\text { Arterial cannulation site } \\
\text { Central } \\
\text { Peripheral } \\
\text { Combination }\end{array}$ & & n.s. \\
\hline $\begin{array}{l}\text { Venous cannulation site } \\
\text { Central } \\
\text { Peripheral }\end{array}$ & & n.s. \\
\hline
\end{tabular}

$C I$, Confidence interval; n.s., not significant; $P C I$, percutaneous coronary intervention; $C A B G$, coronary artery bypass grafting.

examinations with quantitative description of the degree of aortic regurgitation were available from 57 patients $(75 \%)$ and are shown in Table E2.

\section{Late Complications}

Twenty-one patients (15.9\%) discharged alive and without reoperation reported neurological or cerebral events $(P=.650)$. Minor or major bleeding events were reported by 19 patients $(14.4 \% ; P=.734)$.

\section{DISCUSSION}

AAD is a devastating disease with a complex and variable pathology and high acute mortality needing emergent surgical treatment. Patients present often with deteriorating hemodynamics, are intubated, and malperfusion-related comorbidities are not yet completely diagnosed before the procedure. Furthermore, most patients are admitted to hospital at night and the number of patients for a single center is relatively small, thus conditions for this complex surgical intervention are not always optimal. Even more it is crucial to find the situation-related best treatment, to achieve the all-important surgical goal, which is survival of the patient. Our study shows that in this real-world scenario with the different conditions of the groups and the 3 different valve-sparing procedures-remodeling, reimplantation, and valve-sparing root repair-result in not different early mortality and long-term results concerning survival and reoperation. For interpreting the results it must be considered that the surgical technique was adjusted to different criteria such as root pathology and dimension, patients' age and condition, extent of dissection, and surgical experience, which makes comparability difficult. Nevertheless the long-term results of these different techniques are interesting.

\section{Mortality}

Early and late mortality were rather high in this study, but comparable with those reported by some other groups $^{2,12,18}$ and the international registry of aortic dissection. ${ }^{19}$ Reimplantation seems to be a risk factor for overall mortality, probably related to the underlying pathology that needs a more complex and time-consuming procedure like arch replacement. Other factors were also crucial for survival like age at surgery, extent of arch replacement, presence of connective tissue disease, surgical time, shorter cross-clamp time, and absence of circulatory arrest. The fact that the counterintuitive direction of the HR was $<1$ for the cross-clamp time indicated the complexity of the disease and surgery (eg, there was 1 patient with a straight repair of the root needing a relatively short cross-clamp time of 48 minutes but cooling, warming, and reperfusion with several bypass-weaning attempts took a long period of 391 minutes). It was sometimes difficult to diagnose before the surgery malperfusion-related comorbidities, which could per se have a deleterious effect on outcome because a lot of patients arrived at the theatre intubated and often in cardiogenic shock and the diagnosis of AAD was made only after echocardiography was performed. Whether delay of surgery and stabilization in these patients might be a more appropriate approach needs to be evaluated, especially because ventilation, inotropic support, and cardiogenic shock were no risk factors for survival. Olsson and colleagues ${ }^{13}$ reported improving 


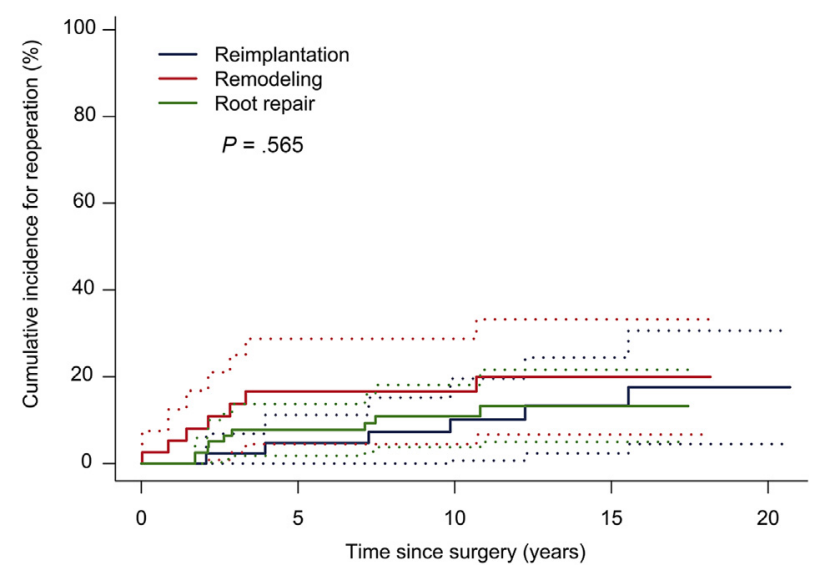

FIGURE 3. Cumulative incidence of reoperation stratified according to surgical technique.

survival in medium-term outcome. They did, however, not differentiate the results in relation to the root reconstruction technique and patients who did not receive surgery were not further specified. Also other groups reported $<10 \%$ hospital mortality. ${ }^{3,20,21}$ In our center the 30-day mortality decreased to $7.7 \%$ in the past 4 years, indicating the general trend of improving early survival of these patients. But the mortality is still too high early and late. Yang and colleagues reported that direct aortic root repair might have a potential survival benefit, ${ }^{22}$ supporting our results with the lowest hazard for late mortality in the root repair group. Nevertheless, these results underline the necessity of close follow-up of all patients after surgery for AAD.

\section{Reoperation}

The reoperation rate in the long-term was not different between the groups and was $13.4 \%$ for remodeling, $20 \%$ for reimplantation, and $13.3 \%$ for valve-sparing root repair at 15 years, which is comparable with other reports. ${ }^{2,20}$ The indications for reoperation varied, so no general cause could be found. The valve-sparing root repair seems to be quite stable. Interestingly, 27 of 96 patients with valve-sparing root repair had some kind of GRF glue used, which was reported to potentially have a negative influence on redissection. ${ }^{14,15}$ Also 3 of our root repair patients in whom GRF glue was used had redissections of the root. Chiu and colleagues ${ }^{20}$ reported that in $83.3 \%$ of reoperations after limited valve-sparing root repair a biological glue had been included in the repair technique. Also in our study $66.7 \%$ of the reoperations in the valve-sparing root repair technique had GRF glue used. In the past 10 years we more or less (depending on the surgeon) did not use GRF or BioGlue between the dissected layers; however, whether GRF use is the predominant reason for reoperation is speculative. Nevertheless the HR was $3.942(P=.053)$; it may be that a larger sample size would shed more light on this

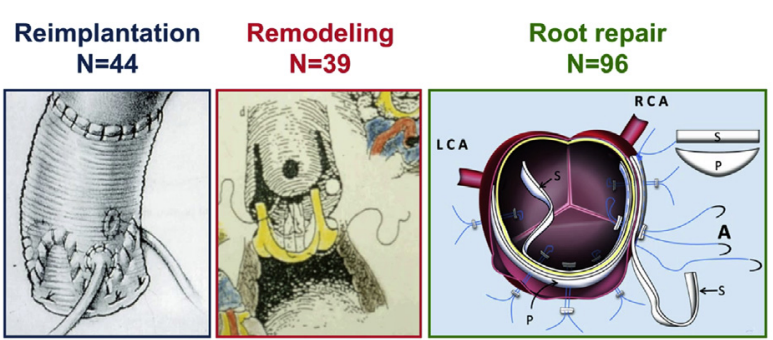

VIDEO 1. Survival and reoperation after valve-sparing root replacement and root repair in acute type A dissection. Video available at: https:// www.jtcvs.org/article/S0022-5223(18)31532-0/fulltext.

issue. One reoperation in the valve-sparing root repair group was because of a dilated annulus, which was primarily repaired with subcommissural sutures. Together the valvesparing root repair technique might probably benefit from nonuse of GRF glue and more appropriate patient selection. It must be kept in mind that valve-sparing root repair was reported to have a higher risk of reoperation ${ }^{20}$ compared with root replacement mainly using bioprostheses or mechanical valve grafts. However, root replacement is also a complex procedure and considerable surgical experience is needed, especially if coronary ostia are involved in the dissection process.

Taken together, our own experience and that of other group $^{23}$ indicate that the more conservative, less complex, and surgical time-saving valve-sparing root repair offers an appropriate technique in selected patients with AAD. For experienced surgeons the choice of a special surgical valve-preserving technique is related to different criteria, whereby valve-sparing root repair requires the least experience and provides adequate results especially if surgical time needs to be shortened in multimorbid patients. ${ }^{24}$

\section{Limitations}

This is a retrospective study with all its shortcomings, especially with unknown confounders that might influence the results; however, prospective randomized trials are questionable to be performed in this patient cohort. The number of patients is relatively small. Pre- or intraoperative root dimensions were not recorded, thus the indications for the different procedures are more or less on the basis of eyeballing and the experience of the surgeon, impairing comparability and generalizability. In addition, it must be considered that there are significant differences in the patient groups, therefore the interpretation of the overall mortality in the groups must include these patient differences. Furthermore there might be confounding at the surgical level, however, this is a real world scenario of a single cardiovascular unit with all of its ever-changing conditions, giving some practical insight in the management of the dissected root in patients with AAD. The echocardiographic follow-up is incomplete but there were no patients 
discovered on the waiting list for reoperation. Furthermore, we did not provide longitudinal echocardiographic evaluation of aortic insufficiency. Therefore we decided not to perform a statistical analysis.

\section{CONCLUSIONS}

In our study with the different conditions in the 3 groups, valve-sparing root repair in patients with AAD offers a less complex and faster surgery with similar long-term survival and reoperation pattern compared with valve-preserving root replacement techniques (Video 1). Individualized approach, related to extent of pathology, patient's condition, and surgeon's experience might include valve-sparing root repair. Longer-term multicenter follow-up is desirable to verify this strategy.

\section{Conflict of Interest Statement}

Drs Sievers, Diwoky, Auer, Bucsky, Nasseri, and Klotz report receiving royalties for vascular prostheses from B. Braun Melsungen outside the submitted work. All other authors have nothing to disclose with regard to commercial support.

\section{References}

1. Lai DT, Miller DC, Mitchell RS, Oyer PE, Moore KA, Robbins RC, et al. Acute type A aortic dissection complicated by aortic regurgitation: composite valve graft versus separate valve graft versus conservative valve repair. J Thorac Cardiovasc Surg. 2003;126:1978-86.

2. Beckmann E, Martens A, Pertz J, Kaufeld T, Umminger J, Hanke JS, et al. Valvesparing David I procedure in acute aortic type A dissection: a 20-year experience with more than 100 patients. Eur J Cardiothorac Surg. 2017;52:319-24.

3. Leshnower BG, Myung RJ, McPherson L, Chen EP. Midterm results of David V valve-sparing aortic root replacement in acute type A aortic dissection. Ann Thorac Surg. 2015;99:795-800; discussion 801.

4. Urbanski PP, Lenos A, Irimie V, Bougioukakis P, Zacher M, Diegeler A. Acute aortic dissection involving the root: operative and long-term outcome after curative proximal repair. Interact Cardiovasc Thorac Surg. 2016;22:620-6.

5. Bentall H, De Bono A. A technique for complete replacement of the ascending aorta. Thorax. 1968;23:338-9

6. David TE, Feindel CM. An aortic valve-sparing operation for patients with aortic incompetence and aneurysm of the ascending aorta. J Thorac Cardiovasc Surg. 1992:103:617-21; discussion 622.

7. Sarsam MA, Yacoub M. Remodeling of the aortic valve anulus. J Thorac Cardiovasc Surg. 1993;105:435-8.

8. Price J, Magruder JT, Young A, Grimm JC, Patel ND, Alejo D, et al. Long-term outcomes of aortic root operations for Marfan syndrome: a comparison of Bentall versus aortic valve-sparing procedures. J Thorac Cardiovasc Surg. 2016;151: 330-6.

9. Esaki J, Leshnower BG, Binongo JN, Lasanajak Y, McPherson L, Halkos ME et al. The David V valve-sparing root replacement provides improved surviva compared with mechanical valve-conduits in the treatment of young patients with aortic root pathology. Ann Thorac Surg. 2016;102:1522-30.

10. DeNino WF, Toole JM, Rowley C, Stroud MR, Ikonomidis JS. Comparison of David V valve-sparing root replacement and bioprosthetic valve conduit for aortic root aneurysm. J Thorac Cardiovasc Surg. 2014;148:2883-7.

11. Parikh N, Trimarchi S, Gleason TG, Kamman AV, di Eusanio M, Myrmel T, et al. Changes in operative strategy for patients enrolled in the International Registry of Acute Aortic Dissection interventional cohort program. J Thorac Cardiovasc Surg. 2017;153:S74-9.

12. Subramanian S, Leontyev S, Borger MA, Trommer C, Misfeld M, Mohr FW Valve-sparing root reconstruction does not compromise survival in acute type A aortic dissection. Ann Thorac Surg. 2012;94:1230-4

13. Olsson C, Ahlsson A, Fuglsang S, Geirsson A, Gunn J, Hansson EC, et al. Medium-term survival after surgery for acute type A aortic dissection is improving. Eur J Cardiothorac Surg. 2017;52:852-7.

14. Kazui T, Washiyama N, Bashar AH, Terada H, Suzuki K, Yamashita K, et al. Role of biologic glue repair of proximal aortic dissection in the development of early and midterm redissection of the aortic root. Ann Thorac Surg. 2001;72:509-14.

15. Erasmi AW, Stierle U, Bechtel JF, Schmidtke C, Sievers HH, Kraatz EG. Up to 7 years' experience with valve-sparing aortic root remodeling/reimplantation for acute type A dissection. Ann Thorac Surg. 2003;76:99-104.

16. Leyh RG, Schmidtke C, Sievers HH, Yacoub MH. Opening and closing charac teristics of the aortic valve after different types of valve-preserving surgery. Cir culation. 1999:100:2153-60.

17. Clark TG, Altman DG, De Stavola BL. Quantification of the completeness of follow-up. Lancet. 2002;359:1309-10.

18. Estrera AL, Sandhu HK, Leake SS, Charlton-Ouw KM, Afifi RO, Miller CC III, et al. Early and late outcomes of acute type A aortic dissection with intramural hematoma. J Thorac Cardiovasc Surg. 2015;149:137-42.

19. Pape LA, Awais M, Woznicki EM, Suzuki T, Trimarchi S, Evangelista A, et al Presentation, diagnosis, and outcomes of acute aortic dissection: 17-year trends from the International Registry of Acute Aortic Dissection. J Am Coll Cardiol. 2015;66:350-8.

20. Chiu P, Trojan J, Tsou S, Goldstone AB, Woo YJ, Fischbein MP. Limited root repair in acute type A aortic dissection is safe but results in increased risk of reoperation. J Thorac Cardiovasc Surg. 2018;155:1-7.e1.

21. Tang Y, Liao Z, Han L, Tang H, Song Z, Xu Z. Long-term results of modified sandwich repair of aortic root in 151 patients with acute type A aortic dissection. Interact Cardiovasc Thorac Surg. 2017;25:109-13.

22. Yang B, Malik A, Waidley V, Kleeman KC, Wu X, Norton EL, et al. Short-term outcomes of a simple and effective approach to aortic root and arch repair in acute type A aortic dissection. J Thorac Cardiovasc Surg. 2018;155:1360-70.e1.

23. Westaby S, Saito S, Katsumata T. Acute type A dissection: conservative methods provide consistently low mortality. Ann Thorac Surg. 2002;73:707-13.

24. David TE, David CM, Feindel CM, Manlhiot C. Reimplantation of the aortic valve at 20 years. J Thorac Cardiovasc Surg. 2017;153:232-8.

Key Words: acute type A dissection, remodeling, reimplantation, aortic root repair 


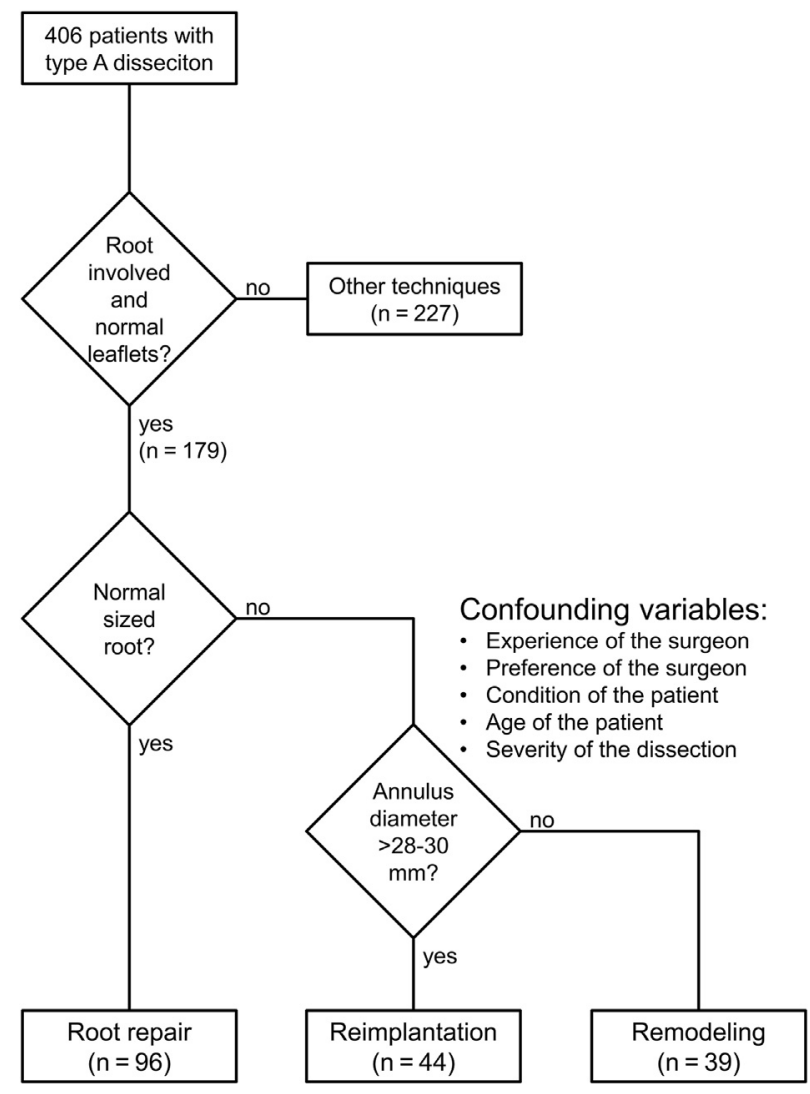

FIGURE E1. General algorithm for surgical strategy.

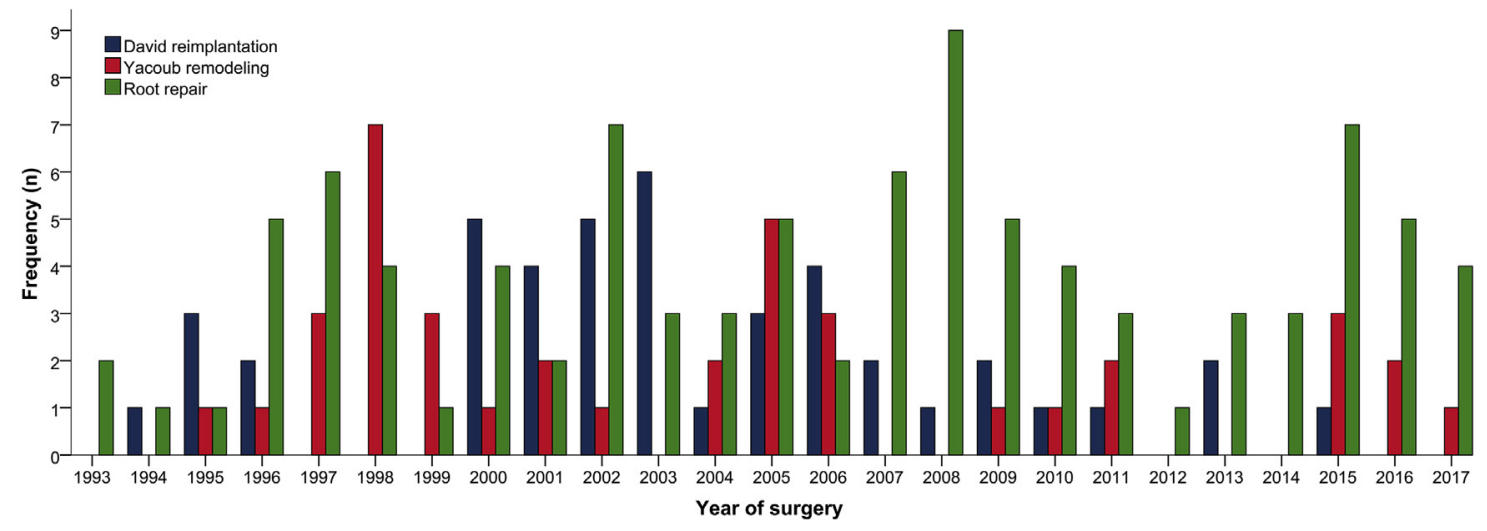

FIGURE E2. Histogram showing the number of the different procedures over the years. 
TABLE E1. Reasons for reoperation

\begin{tabular}{lll}
\hline \multicolumn{1}{c}{ Technique } & \multicolumn{1}{c}{ Cause of reoperation } & $\mathbf{n}$ \\
\hline Reimplantation $(\mathrm{n}=6)$ & Leaflet deterioration (GRF) & 5 \\
& Right commissure prolapse & 1 \\
\hline Remodeling $(\mathrm{n}=7)$ & Leaflet deterioration (GRF) & 2 \\
& Leaflet deterioration (no GRF) & 1 \\
& False root aneurysms (GRF) & 1 \\
& Rupture of the noncoronary leaflet & 1 \\
& nearby the commissures & \\
& Ruptured fenestration noncoronary & 1 \\
& leaflet & 1 \\
\hline Valve-sparing root & Unknown (GRF) & 3 \\
repair $(\mathrm{n}=9)$ & Aortic root redissection (GRF) & 2 \\
& & 2 \\
\hline & Root aneurysm (GRF) & 1 \\
\hline & Root aneurysm (no GRF) & 1 \\
\hline & Endocarditis (GRF) & \\
\hline
\end{tabular}

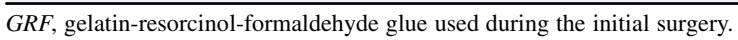

TABLE E2. Latest echocardiographic examination

\begin{tabular}{lccr}
\hline & Reimplantation $(\mathbf{n}=\mathbf{1 3})$ & Remodeling $(\mathbf{n}=\mathbf{1 1})$ & Root repair $(\mathbf{n}=\mathbf{3 3})$ \\
\hline Aortic regurgitation & & & \\
$\quad$ None & $6(46.2)$ & $2(18.2)$ & $6(18.2)$ \\
Trace & $3(23.1)$ & 0 & $12(36.4)$ \\
Mild & $2(15.4)$ & $5(45.5)$ & $9(27.3)$ \\
Moderate & $2(15.4)$ & $4(36.4)$ & $6(18.2)$ \\
Median time to & $13.2(7.6-15.8)$ & $10.4(1.5-14.6)$ & $5.9(0.8-11.0)$ \\
echocardiography, y & $0.9-20.6$ & $0-18.2$ & $0.1-17.1$ \\
\hline
\end{tabular}

Only alive patients without aortic valve reoperation and echocardiographic examination in the past 2 years were considered. The time to echocardiography was presented as median with interquartile range and range. 